better with the $A l u I$-Giemsa technique.

SUNNY LUKE, RAM S VERMA Division of Genetics, The Long Island College Hospital-SUNY Health Science Center at Brooklyn, Atlantic Avenue \& Hicks Street, New York, NY 11201, USA.

1 Verma RS, ed. Heterochromatin: molecular and structural aspects. New York: Cambridge University Press, 1988; 276-92.

2 Soudek D, Sroka $H$. Inversion of 'fuorescent' segment in chromosome 3: a polymorphic trait. Hum Genet 1978; 44:109-15.

3 Petrovic V. A new variant of chromosome 3 with unusual staining properties. F Med Genet 1988;25:781-2.

4 Verma RS, Luke S, Conte RA, Macera MJ. A so called rare heteromorphism of the human genome. Cytogenet Cell Genet 1991;56:63.

5 Verma RS. The genome. New York: $\mathrm{VCH}$ Press, 1990;43-72.

6 Verma RS, Babu A. Human chromosomes: manual of basic techniques. New York: Pergamon Press, 1989:45-52.

7 Babu A, Agarwal AK, Verma RS. A new approach in recognition of heterochromatic regions of human chromosomes by means of restriction endonuclease. Am $f$ Hum Genet 1988;42:60-5.

8 Willard HF. Centromeres of mammalian chromosomes. Trends Genet 1990; 6:410-6.

9 Babu A, Verma RS. Chromosome structure: euchromatin and heterochromatin. Int Rev Cytol 1987;108:1-60.

\section{Cystic fibrosis in Bulgaria}

In an article published in the journal, Cuppens et al described a cystic fibrosis patient who was homozygous for the G542X mutation yet presented with a relatively mild clinical picture.

This mutation, although rarer than $\triangle F 508$, seems to occur in all European populations. In the Bulgarian CF patients we are testing it is found at a frequency of $5 \%$ of CF alleles. So far we have detected six patients with G542X including one homozygote (table). The clinical course of the disease is invariably severe in our patients. Symptoms of CF had been present from the first months of life and in all cases the diagnosis had been established during the first year. Taking into account the fact that CF is often diagnosed late in this country, early diagnosis suggests a severe course of the disease. At present only one out of the six patients with G542X is still living. Early infant death occurred in four of the families (in two of them a previous affected

Bulgarian cystic fibrosis patients with G542X

\begin{tabular}{|c|c|c|}
\hline Patient No & Mutations & Family and clinical data \\
\hline 33 & G542X/G542X & $\begin{array}{l}\text { Index patient and affected sister died } \\
\text { in infancy }\end{array}$ \\
\hline 3 & G542X/ $\triangle$ F508 & $\begin{array}{l}\text { Index patient and affected brother } \\
\text { died in infancy }\end{array}$ \\
\hline $\begin{array}{l}54 \\
74 \\
28\end{array}$ & $\begin{array}{l}\text { G542X/ } / \triangle \text { F508 } \\
\text { G542X/ } / \triangle 508 \\
\text { G542X/S549N }\end{array}$ & $\begin{array}{l}\text { Pulmonary involvement, still living } \\
\text { Meconium ileus, died at } 4 \text { days } \\
\text { Pulmonary involvement, died at } 7 \\
\text { years }\end{array}$ \\
\hline 66 & G542X/N1303K & Meconium ileus, died at 10 days \\
\hline
\end{tabular}

child had also died at a very early age). Two patients had meconium ileus (MI); this has been recorded in about $10 \%$ of our CF patients and thus seems to be over-represented in the G542X subgroup (seven $\mathrm{MI}$ out of a total of $78 \mathrm{CF}$ patients and two MI out of six with G542X).

Our findings are thus in agreement with the assumption that a stop codon at position 542 results in the synthesis of a functionally inactive protein. On the other hand an increasing number of publications, as well as our own observations, suggest that in a number of patients the actual clinical findings conflict with the molecular evidence. Heterogeneity within groups with the same molecular defect could suggest the existence of additional, perhaps genetic, factors which modify the clinical course of cystic fibrosis.

\section{KALAYDJIEVA, D ANGELICHEVA Laboratory of Molecular Pathology, Institute of Obstetrics, Medical Academy, 2 Zdrave Street, Sofia 1431, Bulgaria. \\ I GALEVA, V LALOV Chest Clinic, Institute of Pediatrics, Medical Academy, $1 G$ Sofisky Street Sofia 1431, Bulgaria. \\ D KONSTANTINOVA Genetic Centre, \\ Higher Medical Institute, Varna, Bulgaria.}

Cuppens H, Marynen P, De Boeck C, et al. A child, homozygous for a stop codon in exon 11, shows milder cystic fibrosis symptoms than her heterozygous nephew. $\mathcal{F}$ Med Genet 1990;27:717-9.

\section{Floating Harbor and the good ship Shprintzen}

I would like to take issue with the authors of the 'Syndrome of the month' concerning the Floating Har- bor syndrome, ${ }^{1}$ particularly their penultimate patient number 1 . This looks to me very much like a case of velocardiofacial (Shprintzen) syndrome on the basis of facial phenotype, especially speech delay, immobile palate, malocclusion, and pulmonary stenosis. Pulmonary stenosis can be associated with the Shprintzen syndrome. ${ }^{23}$ The facial dysmorphism appears typical in this photograph: deficient alae, high nasal bridge, almond shaped palpebral fissures, myopathic facies, and maxillary and mandibular hypoplasia. This patient does not have a large mouth. Immobile palate is of particular interest and I would suggest that this patient be reviewed as regards submucous cleft of the palate. Even if it is not obviously present, it may well be at operation. Videofluoroscopy of the palate would be of some assistance in this regard. These patients are uniformly unresponsive to speech therapy and respond only to palate lengthening or pharyngoplasty or both.

It is clear that if there is some considerable doubt about the first patient the other reported patients need to be reviewed. The details supplied were not adequate enough to determine if other syndromes or small, odd-looking children have been lumped together under this enticing name. In particular, actual height centiles would be of interest. Patients with the velocardiofacial (Shprintzen) syndrome are small, but not several standard deviations below the mean.

ANTHONY LIPSON Genetics and Dysmorphology Unit, The Children's Hospital, Pyrmont Bridge Road, Camperdown, Sydney 2050, Australia.

1 Patten MA, Hurst J, Donnai D, McKeown CME, Cole T, Goodship J. Floating-Harbor syndrome. $\boldsymbol{f} \mathrm{Med}$ Genet 1991;28:201-4. 